\title{
Assessment of Staff Nurses' Competencies Related to Safety Measure for Specific Practices
}

\author{
Shaimaa Talaat Osman 1Mona Abo Ziad Khalifa 2, Safaa Mohammed Abd Elrahman 3
}

1 B. Sc in Nursing, Minia University, Egypt.

2 Professor of public Health, Faculty of Medicine - Minia University, Egypt.

3 Assistant Professor of Nursing Administration, Faculty of Nursing - Minia University, Egypt.

\section{Abstract}

Background: Nursing competency and safety of nursing practice are major concerns in nursing educational and clinical practice settings that decrease errors made by nurses. The National Council of State Boards of Nursing (NCSBN) report in 2005 indicated that $25 \%$ of sentinel events in healthcare were related to nursing errors and the majority of these errors related to incompetence of health care workers. Aim of the study: to assess staff nurses' competencies related to safety measure for specific practices. Research design: Descriptive research design was used in this study. Sample: Sixty nurses. Setting: Medical and Surgical Department at Minia University Hospital and Matai District Hospital. Tool of data collection: one tool, divided into two parts, part (1) included sociodemographic data sheet and part (2) included check list performance. Results: it was noted that two-third (63.3\%) of nurses at Minia University Hospital didn't do the infection control measures compared to only one-third (33.3\%) among Matai Hospital. There was statistical significant positive correlation between infection control competency, medication administration safety and environmental safety in both hospitals $(p=0.001)$. Also, this study revealed that there is low competency level of staff nurses due to the lack of nursing competency assessment for nurses. Conclusion: this study revealed that there is low competency level of staff nurses, also it is important for integrating a structured nursing competency assessment that measures nursing competence in the nursing care delivery systems and determining the competency levels of nurses to ensure safe nursing practice. Recommendation: Provide selfcompetency assessment checklist which assists nurses to identify, maintain, and improve their nursing practice Keywords: Nursing competency, safety of nursing practice.

\section{Introduction}

Nurses have differing degrees of autonomy and different responsibilities in the provision of competent patient care within the legal and ethical boundaries of the nursing practice that based on their training, education, and needs of the organization. Also, nurses are expected to perform competently in their various roles as healthcare providers, teachers, research consumers, policy makers, client advocates, counselors, team players, case managers, organizers, administrators, community leaders, specialists, and consultants. Nurses demonstrate their competence in knowledge, skills, and appropriate attitudes that are related to technical skills, clinical practice, critical thinking, human relations, and organizational behavior on an ongoing basis. $(1,2,3)$

The continuing competency assessment of nurses are essential to their professional growth, confidence in the workplace, and for providing safe and positive experience of patients. Patient safety is an essential and vital component of quality care. Yet health care providers face many challenges in today's health care environment in trying to keep patients safe. Thus safety of nursing practice takes place through nursing education and ensuring that clinical practices meet the evidence-based practice, accreditation, and the certification requirements, as well providing high level of competency to nursing. $(4,5)$

Furthermore, continual change in nursing practice is due to the incorporation of evidence-based interventions and improvements in technologies which lead to continue the assessment of nurses competency, that can be achieved through the ongoing nursing competency assessment and based on a standard of nursing practices that allow nurses to self-monitor, increase their strengths, improve weaknesses,

P a g e | 104 demonstrate their abilities, and identify gaps in knowledge, skills and attitude to maintain a high standard of nursing practices. (6)

The nursing competency-based practice framework describes the core competency standards for the advanced level of nursing practice that is related to complexity, and innovative to achieve optimal patient outcomes. Developing competency-based practice standards for nurses with advanced degrees is important to balance between education and clinical practice to assess nursing knowledge, clinical skills, and attitudes in complex clinical situations. Without a well-structured nursing competency assessment, nursing leaders and nurse mangers could face difficulties in protecting the public from malpractice, errors, and sustaining the credibility of nursing as a profession. $(7,8)$

\section{Significance of the Study}

The assessment of nursing competence reflects a nurse's own job performance in ensuring safe nursing practice. The nursing competency assessment is a fundamental mechanism to measure the level of nursing competence and validate whether nurses are competent or incompetent and involve performing their assigned jobs efficiently and safely. There were many studies that reported the rise in nursing errors and how the nursing competence can influence on the safety of nursing practice, (NCSBN) report in 2005 indicated that $25 \%$ of sentinel events in healthcare were related to nursing errors and the majority of these errors related to incompetence of health care workers, for this the staff nurses need to be more competent to ensure safe nursing practice (9). Thus this study will describe the 
level of nursing competence among staff nurses in their work.

\section{Aim of the study}

The aim of the current study is to assess staff nurses' competencies related to safety measure for specific practices at Minia university hospital and Matai district hospital affiliated to Ministry of health in Minia government.

\section{Research question} staff nurses?

What is the level of nursing competence among

\section{Subjects and methods \\ Study design:}

Descriptive research design was utilized to achieve the aim of the current study.

\section{Setting:}

This study was conducted in Medical and Surgical Department at Minia university Hospital and Matai District Hospital who affiliated to Ministry of health in Minia government.

\section{Sample size:}

The subjects of the study consisted of all the available staff nurses working in Medical and Surgical Department at Minia University Hospital and Matai District Hospital who affiliated to Ministry of health in Minia government, the total number were 60 nurses, which were selected by simple random sample.

\section{Data collection tool}

Data was collected through utilization of one tool divided into two parts as follows:

\section{Part (1) - Socio-demographic data sheet}

It was used to collect data about the sociodemographic characteristics of the study participants; it included (age, gender, education, job title, and total years of experience in profession).

\section{Part (2) - Check list performance}

It was used to assess nursing performance, which developed by Ministry of Health in Saudi Arabia (nursing competency program, 2009) and Nadia A. Fentianah (2012). $(10,11)$ The tool was included three nursing core competencies that selected from six. The three selected core competencies included 29 items divided as infection control, which consisted of (10 items), medication administration safety, which consisted of (11 items) and environmental safety, which consisted of ( 8 items), each item was checked by researcher through observing staff nurses during the performance of their assigned duties. The response for each item was checked as (done correctly $=2$, done incorrectly $=1$, and not done $=0$ ) and the scoring system was ranged from 0 to 58 . The total score calculated by converting score into percentage $\%$ of performed care as follows (done correctly $>75 \%$, done incorrectly from $(74 \%-50 \%)$ and Not done $<50 \%$ ).

\section{Validity and Reliability of the tool}

The tool was tested for content validity by a jury of experts in the field of the study.

\section{Data collection procedure}

An official letter was granted from the director of Minia University Hospital and Matai District Hospital, staff nurses was interviewed on individual basis to explain the nature and purpose of the study, the researcher assessed nurse's performance through observation of them while performing their assigned jobs. The researcher observed nurse's performance two days per week and two nurses were taken per day.

\section{Pilot study}

A pilot study was done to test the feasibility of the study and applicability of the tool and the necessary modifications were done. The pilot study was done on $10 \%$ of nurses whom were included in the study.

\section{Ethical Consideration}

- A written initial approval was obtained from the research ethical committee in the Faculty of Nursing, Minia University.

- Approval to conduct the study from the director of Minia University Hospital and director of Matai District Hospital, informed consent was obtained by the investigator from the nurse.

- Explanation about the study was done to the nurses included the aim of the study, potential benefits, and participants was informed of withdrawal procedures if they decided to leave the study at any time before, during, and or after the completion of data collection,

- Confidentiality of data, privacy, identity, voluntary participation and right to refuse to participate in the study was emphasized to subjects.

\section{Statistical analysis}

Data was collected tabulated and analyzed using suitable statistical tests. Data entry and analysis were all done with I.B.M. compatible computer using software called SPSS for windows version 19. Graphics were done by Excel Microsoft office 2003. Quantitative data were presented by mean and standard deviation, while qualitative data were presented by frequency distribution. Chi square test, and Z (test of proportions) test was used to compare between proportions. Student t-test was used to compare two. Correlation test was used to test association between the studied scores, the probability of less than 0.05 was used as a cut off point for all significant tests. 


\section{Results}

Table (1): socio- demographic data of the staff nurses

\begin{tabular}{|c|c|c|c|c|c|c|}
\hline \multirow[t]{2}{*}{ Personal characteristic } & \multicolumn{2}{|c|}{$\begin{array}{l}\text { Matai hospital } \\
\text { N } 30\end{array}$} & \multicolumn{2}{|c|}{$\begin{array}{l}\text { Minia university } \\
\text { hospital } \\
\mathbf{N}=\mathbf{3 0}\end{array}$} & \multirow[t]{2}{*}{$\mathrm{X} 2$} & \multirow[t]{2}{*}{$\mathbf{p}$} \\
\hline & $\mathbf{N}$ & $\%$ & $\mathbf{N}$ & $\%$ & & \\
\hline $\begin{array}{l}\text { Age } \\
20-30 y \\
31-41 y \\
42-52 y\end{array}$ & $\begin{array}{l}12 \\
12 \\
6\end{array}$ & $\begin{array}{l}40 \\
40 \\
20\end{array}$ & $\begin{array}{l}23 \\
7 \\
0\end{array}$ & $\begin{array}{l}76.7 \\
23.3 \\
0\end{array}$ & 10.7 & $0.005^{*}$ \\
\hline $\begin{array}{l}\text { Gender } \\
\text { Male } \\
\text { Female }\end{array}$ & $\begin{array}{l}4 \\
26\end{array}$ & $\begin{array}{l}13.3 \\
86.7\end{array}$ & $\begin{array}{l}5 \\
25\end{array}$ & $\begin{array}{l}16.7 \\
83.3\end{array}$ & 0.13 & 0.7 \\
\hline $\begin{array}{l}\text { Education } \\
\text { Diploma degree } \\
\text { Bachelor Degree }\end{array}$ & $\begin{array}{l}26 \\
4\end{array}$ & $\begin{array}{l}86.7 \\
13.3\end{array}$ & $\begin{array}{l}28 \\
2\end{array}$ & $\begin{array}{l}93.3 \\
6.7\end{array}$ & 5.2 & $0.03 *$ \\
\hline $\begin{array}{l}\text { Job } \\
\text { Nurse } \\
\text { Head nurse } \\
\text { Nurse supervisor }\end{array}$ & $\begin{array}{l}18 \\
6 \\
6\end{array}$ & $\begin{array}{l}60 \\
20 \\
20\end{array}$ & $\begin{array}{l}26 \\
4 \\
0\end{array}$ & $\begin{array}{l}86.7 \\
13.3 \\
0\end{array}$ & 8.5 & $0.02 *$ \\
\hline $\begin{array}{l}\text { Years of experience } \\
1-5 y \\
5-10 y \\
10-15 y \\
15-20 y\end{array}$ & $\begin{array}{l}5 \\
8 \\
2 \\
15\end{array}$ & $\begin{array}{l}16.7 \\
26.7 \\
6.7 \\
50\end{array}$ & $\begin{array}{l}12 \\
14 \\
3 \\
1\end{array}$ & $\begin{array}{l}40 \\
46.7 \\
10 \\
3.3\end{array}$ & 16.9 & $0.001 *$ \\
\hline
\end{tabular}

\section{$*=$ significant results $\mathrm{p}$.}

Table (1) illustrates the socio- demographic personal characteristic about the staff nurses, the age of study nurses in Matia Hospital were equal percent (40\%) for the ages between 20-30 year and 31-41year; while the majority of nurses age $(76.7 \%)$ in Minia university hospital was ranged between 20-30 year. Regarding gender, it was observed that the majority of staff nurses in Matia and Minia University Hospitals $(86.7 \%, 83.3 \%$ respectively) were females. About the education level, the majority of study nurses in Matai hospital (86.7\%) had diploma degree, while (93.3\%) staff nurses in Minia University Hospital had diploma degree with statistically significant difference $(\mathrm{p}=$ 0.03 ). Regarding years' experience, it was noted that half of staff nurses in Matia Hospital had 15 -20years of experience but, near the half of nurses in Minia University Hospital $(46.7 \%)$ had 5-10years of experience, with statistical significant difference $(\mathrm{p}=0.001)$.

Table (2): total scores of safety measures practice related to staff nurses' competencies

\begin{tabular}{|c|c|c|c|c|c|c|}
\hline \multirow[t]{2}{*}{ items } & \multicolumn{2}{|c|}{$\begin{array}{c}\text { Matai Hospital } \\
\qquad \mathbf{N}=\mathbf{3 0}\end{array}$} & \multicolumn{2}{|c|}{$\begin{array}{c}\text { Minia University } \\
\text { Hospital } \\
\mathbf{N}=\mathbf{3 0}\end{array}$} & \multirow[t]{2}{*}{$\mathbf{X} 2$} & \multirow[t]{2}{*}{$\mathbf{P}$} \\
\hline & $\mathbf{N}$ & $\%$ & $\mathbf{N}$ & $\%$ & & \\
\hline 1- Infection control score & & & & & & \\
\hline Done correctly & 10 & 33.3 & $\mathbf{0}$ & $\mathbf{0}$ & & \\
\hline Done incorrectly & 10 & $r r, r$ & 11 & 36.7 & $X 2=12.8$ & $0.002 *$ \\
\hline Not done & 10 & 33.3 & 19 & 63.3 & & \\
\hline Range & \multicolumn{2}{|c|}{$2-15$} & \multicolumn{2}{|c|}{$1-11$} & \multirow{2}{*}{$\mathrm{t}=\mathbf{1 5 . 7}$} & \multirow{2}{*}{$0.001 *$} \\
\hline Mean \pm SD & \multicolumn{2}{|c|}{$9.06 \pm 3.6$} & \multicolumn{2}{|c|}{$5.6 \pm 3.07$} & & \\
\hline $\begin{array}{l}\text { 2- Medication administration } \\
\text { safety score }\end{array}$ & & & & & & \\
\hline
\end{tabular}




\begin{tabular}{|c|c|c|c|c|c|c|}
\hline \multirow[t]{2}{*}{ items } & \multicolumn{2}{|c|}{$\begin{array}{c}\text { Matai Hospital } \\
\qquad \mathbf{N}=\mathbf{3 0}\end{array}$} & \multicolumn{2}{|c|}{$\begin{array}{c}\text { Minia University } \\
\text { Hospital } \\
\mathbf{N}=\mathbf{3 0}\end{array}$} & \multirow[t]{2}{*}{$\mathbf{X} 2$} & \multirow[t]{2}{*}{$\mathbf{P}$} \\
\hline & $\mathbf{N}$ & $\%$ & $\mathbf{N}$ & $\%$ & & \\
\hline Done correctly & 11 & 36.7 & $\mathbf{0}$ & $\mathbf{0}$ & & \\
\hline Done incorrectly & 6 & 20 & 8 & 26.7 & $X 2=13.6$ & $0.001 *$ \\
\hline Not done & 13 & 43.3 & 22 & 73.3 & & \\
\hline Range & \multicolumn{2}{|c|}{$2-16$} & \multicolumn{2}{|c|}{$1-11$} & \multirow[t]{2}{*}{$\mathrm{t}=9.4$} & \multirow[t]{2}{*}{ 0.003* } \\
\hline Mean \pm SD & \multicolumn{2}{|c|}{$7.8 \pm 4.9$} & \multicolumn{2}{|c|}{$5.5 \pm 1.8$} & & \\
\hline 3- Environmental safety score & & & & & & \\
\hline Done correctly & 8 & 26.7 & 1 & 3.3 & $\mathrm{X} 2=16.8$ & $0.001 *$ \\
\hline Done incorrectly & 7 & 23.3 & $\mathbf{0}$ & $\mathbf{0}$ & & \\
\hline Not done & 15 & 50 & 29 & 96.7 & & \\
\hline Range & \multicolumn{2}{|c|}{$1-12$} & \multicolumn{2}{|c|}{$0-11$} & \multirow[t]{2}{*}{$\mathrm{t}=\mathbf{2 3 . 3}$} & \multirow[t]{2}{*}{$0.001 *$} \\
\hline Mean \pm SD & \multicolumn{2}{|c|}{$5.6 \pm 3.1$} & \multicolumn{2}{|c|}{$1.6 \pm 2.2$} & & \\
\hline
\end{tabular}

Table (2) shows the total scores of safety measures practice related to staff nurses' competencies. Regarding, infection control measures score, it was noted that mean score among staff nurses was $(9.06 \pm 3.6)$ at Matai Hospital, while it was $(5.6 \pm 3.07)$ at Minia University Hospital with statistically significant difference between both hospital $(\mathrm{t}=15.7, \mathrm{p}=0.001)$.

Regard the total score of medication administration safety competency, it was showed that the mean score of nurse's performance for medication administration competency was (7.8 \pm 4.9$)$ at Matai Hospital, while it was $(5.5 \pm 1.8)$ at Minia University hospital with high statistically significant difference between both hospital ( $t=9.4$, $\mathrm{p}=0.003$ ).

Furthermore, it was noticed from the same table, the mean score of nurse's performance for environmental safety competency was $(5.6 \pm 3.1)$ at Matai Hospital, in comparison, it was (1.6 \pm 2.2$)$ at Minia University Hospital with statistically significant difference between both hospital $(\mathrm{t}=23.3, \mathrm{p}=0.001)$.

Table (3): correlation between the studied Hospitals scores

\begin{tabular}{|c|c|c|c|c|c|}
\hline Hospitals & \multicolumn{2}{|l|}{ items } & $\begin{array}{l}\text { infection control } \\
\text { competency }\end{array}$ & $\begin{array}{c}\text { medication } \\
\text { administration safety }\end{array}$ & $\begin{array}{l}\text { Environmental } \\
\text { Safety }\end{array}$ \\
\hline \multirow{6}{*}{$\begin{array}{c}\text { Matai } \\
\text { hospital }\end{array}$} & \multirow{2}{*}{ infection control competency } & $\mathrm{r}$ & --- & 0.829 & 0.788 \\
\hline & & $\mathrm{p}$ & --- & $0.001 *$ & $0.001^{*}$ \\
\hline & \multirow{2}{*}{$\begin{array}{l}\text { medication administration } \\
\text { safety }\end{array}$} & $\mathrm{r}$ & 0.829 & --- & 0.837 \\
\hline & & $\mathrm{p}$ & $0.001^{*}$ & --- & $0.001^{*}$ \\
\hline & \multirow{2}{*}{ environmental Safety } & $\mathrm{r}$ & 0.788 & 0.837 & --- \\
\hline & & $\mathrm{p}$ & $0.001 *$ & $0.001 *$ & --- \\
\hline \multirow{6}{*}{$\begin{array}{c}\text { Minia } \\
\text { university }\end{array}$} & \multirow{2}{*}{ infection control competency } & $\mathrm{r}$ & --- & 0.711 & 0.581 \\
\hline & & $\mathrm{p}$ & -- & $0.001 *$ & $0.001^{*}$ \\
\hline & \multirow{2}{*}{$\begin{array}{l}\text { medication administration } \\
\text { safety }\end{array}$} & $\mathrm{r}$ & 0.711 & --- & 0.611 \\
\hline & & $\mathrm{p}$ & $0.001^{*}$ & --- & $0.001^{*}$ \\
\hline & \multirow{2}{*}{ environmental safety } & $\mathrm{r}$ & 0.581 & 0.611 & --- \\
\hline & & $\mathrm{p}$ & $0.001 *$ & $0.001 *$ & --- \\
\hline
\end{tabular}

Table (3) presents a correlation matrix between the two hospitals, it points to statistically significant positive correlation between infection control competency,

\section{Discussion}

The continuing competency assessment of nurses is essential to their professional growth, confidence in the workplace, the safe and positive experience of patients. Multidimensional approaches in nursing assessment should be based on several differing assessments methods. It should medication administration safety and environmental safety in both hospitals $(\mathrm{p}=0.001)$.

be the combination of knowledge, critical thinking, caring and communication, problem-solving, and reflection for safe practice. Lack of adequate competency will result in chaos and disorganization and increase the casualties and property losses, hence nursing competence assessment are essential to 
ensure health care organizations provide safe efficient health care that including public health care. (12)

Regarding the socio-demographic characteristic, more than two-thirds of the study sample age between was (20-30 years old), in Minia University Hospital, while there was equal percent (40\%) between age $20-30 y$ and $31-41$ y at Matia Hospital, as high percent of study sample were females and low percent were males in both hospitals and the majority of participant in the study were diploma nursing school in both hospitals.

As regard total infection control competency measures score, the results revealed that there were twothird of nurses at Minia University Hospital not done infection control measures compared to only one-third among Matai Hospital, this result indicated high significance regarding total infection control competency score between two hospitals. This result can have explained by lack of nurse's knowledge and training regarding the importance of infection control technique, the lack of resources and finally work load due to high patient number.

This was consistent with Abo Al Wafa (2009) and Abo shadi, (2001) who stated that most of nurses not done infection control techniques, because of the inadequacy of training, continuing education which maintain nurse update with new trends and factors which affect on nursing competence toward infection control measures and lack of supplies and resources which decrease nurse comply with an infection control precaution. $(13,14)$

This result was not consistent with Pittet (2001), who stated that high percent of health worker perform infection control measures which are important for staff, patients and careers. They should be given constant reminders of the importance of infection control and the routine measures required to achieve it. (15)

The finding regarding medication administration indicated that there was significant increase of medication administration safety competency measures which done incorrectly among Minia University Hospital compared to Matai Hospital. The finding result can be due to lack of nurse's knowledge about medication administration safety measure which result from the lack of nurse's competency assessment, lack of training courses, also the gap between nursing knowledge and nursing practice which affected directly on nursing skills. In addition to the frustration, dissatisfaction due to work load, high patient number and lack of supervision especially at Minia University Hospital; all these factors had negative impact on safe nursing practice outcome and medication administration error.

This was in agreement with Sakowski and Newman (2008) who recommended that continuing education, training and ongoing assessment of the nursing staff can help to reduce medication errors; and stated medications that are new to the facility should receive high teaching priority, training, and should be aware about how the medication is entering the body; as well as know how to be administered, possible side effects, storage, and toxicity. Also, this is consistent with Dozier (2008) who stated that heavier workloads and shortage of nurses are associated with medication errors. The nursing shortage has increased workloads by increasing the number of patients for which a nurse is responsible. Also, nurses perform many tasks that take them away from the patient's bedside $(16,17)$.

$P$ a g e $\mid \mathbf{1 0 8}$
Nearly the half of study nurses at Matia Hospital not done environmental safety measure, compared to the majority at Minia University. In addition to, there was significant increase of environmental safety competency measure which done incorrectly among Minia University Hospital compared to Matai Hospital. This result can be due to the lack of nurses' awareness about importance of providing safe environment. Moreover, this was consistent with Dennis (2003-2004) who stated that most of worker not aware for importance of providing safe environment and self-discipline in order to avoid exposure to the environmental hazards, they must be aware of the work environment and there should be continually assessment to identify on environmental hazards around the patients (18).

Furthermore, this result was agreement with Fentianah (2012) who stated that two-third of staff nurses were not able to provide a safe environment for patients, visitors and staff, and didn't take in consideration the importance and needs of patient for providing adequate, good lighting and clean dry floors. Also, it was mentioned that the competency levels of skills on the environmental safety that were more than two third of participant nurses categorized in the low competency level of skills (11).

According to correlation between the studied hospitals scores, the results indicated that there were significant positive correlation between infection control competency core with medication administration safety, and environmental safety competency core in both hospitals. Also, this result indicated that the low competency level of nursing in two hospitals which can be due to many factors as the lack of ongoing nursing competency assessment, lack of continuing education and training program, as well the lack of appropriate policies, procedures, and protocols.

Moreover, there is an impact on safety of the practice due to ineffective nurse supervision and control, frustration, and dissatisfaction which is a result from workload and finally lack of resources, supplies and motivation; so the nursing competency assessment is a constitutional mechanism that exists to provide a framework for tracking nurses' competence throughout their careers to ensure that they remain competent and up to date with the current nursing practice and ensuring nursing practice. This is consistent with Black, Allen, Redfern, Muzio, Rushowick et al. (2008) who stated that determining educational, training' needs and providing suitable amounts of resources and supplies help nurses to function safely within their work place. (18)

\section{Conclusion and recommendation}

This study revealed that there is low competency level of nursing staff in both hospitals, also the it is important for integrating a structured nursing competency assessment that measures nursing competence in the nursing care delivery systems and determining the competency levels of nurses to ensure safe nursing practice.

\section{Recommendation is suggested:}

- Making licensing exams for nurses to practice nursing, continuing education and work-based orientation programs, for renewal nursing. 
- $\quad$ Making nursing competency assessment program based on the dynamic process of adopting changes related to the strategic directions of an organization, such as changes in policies, procedures, patient population, and services provided.

- There should be suitable amounts of resources to help nurses and other health care personal to function safely within their work place.

\section{References}

[1]. Larson, K., \& Elliot, R. (2009). Understanding malpractice: A guide for nephrology nurses. Nephrology Nursing Journal, 36(4): 375-377.

[2]. Kozier, B., Erb, G., Berman, A., \& Snyder, S. (2004). Fundamentals of nursing: Concepts, process, and practice (7th ed.). New Jersey: Pearson Prentice Hall.

[3]. Connelly, L., Yoder, L, \& Miner-Williams, D. (2003). A qualitative study of charge nurse competencies. Medical Surgical Nursing, 12(5): 298-306.

[4]. Axley, L. (2008). Competency: A concept Analysis. Nursing Forum, 43(9): 214-222. WileyBlackwell.

[5]. Ironside, P. (2008). Safeguarding patients through continuing competency. The Journal of Continuing Education in Nursing, 39(2): 92-94.

[6]. McKeon, L., Norris, T., Cardell, B., \& Britt, T. (2009). Developing patient-centered care competencies among prelicensure nursing student using simulation. Journal of Nursing Education, 48(12), 711-715. DOI: $10.3928 / 01484834-$ 20091113-06.

[7]. Benner, P., Tanner, C., and Chesla, C. (1996). Expertise in nursing practice: Caring, clinical judgment, and ethics. New York: Springer.

[8]. Whelan, L. (2006). Competency assessment of nursing staff. Orthopedic Nursing Research Library, 25(3), 198-204. ISSN: 0744-6020.

[9]. Agency for Healthcare Research and Quality. (2010). The effect of health care working conditions on patient safety. Bethesda, MD:
AHRQ. Available from:

www.ahrq.gov/clinic/epcsums/worksum.htm

[10]. MOH Nursing Competency Committee (2009). Nursing competency program. Eastern Province, Saudi Arabia: The General Directorate of Health Affairs, Nursing Administration Office.

[11]. Nadia A. Fentianah (2012). Impact of nursing competency on quality of nursing care and safety practice. A Dissertation Presented in Partial Fulfillment of the Recognition for the Degree, Doctor of health administration, University of phoenix.

[12]. Arcand, L. \& Neumann, J. (2005, November). Nursing competency assessment across the continuum of care. The Journal of Continuing Education in Nursing, 36(6), 247-254. PMID: 16372713.

[13]. Abo Al Wafa, (2009). Assessment of nursing performance in neonatal units at El Minia City Hospital. Master thesis in master degree for pediatric nursing.

[14]. Abo shadi, (2001). Assessment of Nursing knowledge and Practice of Universal Precaution, Faculty of Medicine.

[15]. Pittet, D. (2001). Improving adherence to hand hygiene practice: a multidisciplinary approach. Emerging Infectious Diseases, 7(2):234-240 (available at http://www.cdc.gov/ncidod/eid)

[16]. Sakowski, J., Newman, J., Dozier, K.( 2008). Severity of medication administration errors detected by a bar-code medication administration system. Am J Health Syst Pharm.; 65(17):16611666.

[17]. Dozier, K., Hwang, W., Scott, L., Aiken, L., Dinges, D. (2008). The working hours of hospital staff nurses and patient safety. Health Aff (Millwood); 23(4):202-212.

[18]. Black, J., Allen, D., Redfern, L., Muzio, L., Rushowick, B., Balaski, M., Round, B. (2008). Competencies in the context of entry-level registered nurse practice: a collaborative project in Canada. International Nursing Review, 55(2), 171178. PMID: 18477101 